\title{
Bat Astrovirus in Mozambique
}

\author{
Flora Hoarau', Gildas Le Minter', Léa Joffrin ${ }^{1}$, M. Corrie Schoeman², Erwan Lagadec', Beza Ramasindrazana ${ }^{1,3,7}$, \\ Andréa Dos Santos ${ }^{4}$, Steven M. Goodman ${ }^{3,5}$, Eduardo S. Gudo ${ }^{6}$, Patrick Mavingui ${ }^{1}$ and Camille Lebarbenchon ${ }^{1 *}$
}

\begin{abstract}
Astroviruses (AstVs) are responsible for infection of a large diversity of mammalian and avian species, including bats, aquatic birds, livestock and humans. We investigated AstVs circulation in bats in Mozambique and Mayotte, a small island in the Comoros Archipelago located between east Africa and Madagascar. Biological material was collected from 338 bats and tested for the presence of the AstV RNA-dependent RNA-polymerase gene with a pan-AstV semi-nested polymerase chain reaction assay. None of the 79 samples obtained from Mayotte bats (Pteropus seychellensis comorensis and Chaerephon pusillus) tested positive; however, 20.1\% of bats sampled in Mozambique shed AstVs at the time of sampling and significant interspecific variation in the proportion of positive bats was detected. Many AstVs sequences obtained from a given bat species clustered in different phylogenetic lineages, while others seem to reflect some level of host-virus association, but also with AstVs previously reported from Malagasy bats. Our findings support active circulation of a large diversity of AstVs in bats in the western Indian Ocean islands, including the southeastern African coast, and highlight the need for more detailed assessment of its risk of zoonotic transmission to human populations.
\end{abstract}

Keywords: Mammastrovirus, Mayotte, Mozambique, Madagascar, Triaenops afer

Astroviruses (AstVs) are small non-enveloped RNA viruses, transmitted via the fecal-oral route. They have been detected from over 80 vertebrate host species [1], and represent a significant source of morbidity and economic losses. Worldwide, AstVs account for 2 to $9 \%$ of all acute non-bacterial gastroenteritis in children [2]; they are also responsible for diseases in livestock, poultry and domestic pets [3]. In wild animals, AstVs have been mostly detected in bats [4] and in aquatic birds [5], although detection in other host types have been reported, such as in marine mammals [6] and non-human primates [7].

Current knowledge on the epidemiology of AstVs in African bats is limited $[8,9]$. In a previous study, we detected high genetic diversity of AstVs in Malagasy bats [10]. Detection of AstVs on other islands of the western Indian Ocean has not been reported. The goal of this study was to investigate AstV circulation in bats in Mozambique and on Mayotte, a small island in the Comoros archipelago located between east Africa and Madagascar.

\footnotetext{
* Correspondence: camille.lebarbenchon@univ-reunion.fr

${ }^{1}$ Université de La Réunion, UMR Processus Infectieux en Milieu Insulaire Tropical (PIMIT), INSERM 1187, CNRS 9192, IRD 249, 2 rue Maxime Rivière (GIP CYROI), 97490 Sainte-Clotilde, La Réunion, France

Full list of author information is available at the end of the article
}

Biological material was collected on Mayotte at several locations (Bandrele, Chiconi, Coconi, Kwale, Mangajou, Passamainty, Sohoabe, Tsoundzou), in November-December 2014, and in Mozambique (Inhassoro district) in February and May 2015. Bats were captured using mist nets and harp traps. On Mayotte, rectal swabs were obtained with sterile rayon-tipped applicators (Puritan, Guilford, ME, USA) from 21 Pteropus seychellensis comorensis, and droppings were collected from 58 Chaerephon pusillus. Swabs and droppings were placed in $1.5 \mathrm{~mL}$ of Virus Transport Media (VTM; [10]), and were immediately frozen in liquid nitrogen. In Mozambique, one rectal and one buccal swab were collected for each sampled bat. The two swabs were then placed in the same tube, containing $1.5 \mathrm{~mL}$ of VTM, and were immediately frozen in liquid nitrogen. Sampled bat species and number of tested samples are presented in Table 1.

RNA extraction was performed with the QIAamp Viral RNA Mini Kit (QIAGEN, Valencia, CA, USA). Reverse transcription was performed on $10 \mu \mathrm{L}$ of RNA using the ProtoScript II Reverse Transcriptase and Random Primer 6 (New England BioLabs, Ipswich, MA, USA) using a previously published protocol [10]. cDNAs were

(C) The Author(s). 2018 Open Access This article is distributed under the terms of the Creative Commons Attribution 4.0 International License (http://creativecommons.org/licenses/by/4.0/), which permits unrestricted use, distribution, and 
Table 1 Family, species day roosts, and number of bats sampled and tested for the presence of Astroviruses, in Mozambique

\begin{tabular}{|c|c|c|c|c|}
\hline Family & Species & Day roosts & $\mathrm{N}$ tested & $\mathrm{N}$ positive \\
\hline Hipposideridae & Hipposideros caffer & Caves & 57 & 10 \\
\hline Miniopteridae & Miniopterus mossambicus & Caves & 21 & 2 \\
\hline Molossidae & Mops condylurus & Houses & 52 & 1 \\
\hline Nycteridae & Nycteris thebaica & Caves & 14 & 4 \\
\hline \multirow[t]{3}{*}{ Rhinolophidae } & Rhinolophus lobatus & Caves & 9 & 0 \\
\hline & Rhinolophus mossambicus & Caves & 20 & 0 \\
\hline & Rhinolophus rhodesiae & Caves & 31 & 0 \\
\hline Rhinonycteridae & Triaenops afer & Caves & 51 & 35 \\
\hline \multirow[t]{2}{*}{ Vespertilionidae } & Neoromicia nana & Rolled-up banana leaves & 2 & 0 \\
\hline & Scotophilus viridis & Free-flying & 2 & 0 \\
\hline
\end{tabular}

tested for the presence of the AstV RNA-dependent RNA-polymerase (RdRp) gene using a pan-AstV semi-nested polymerase chain reaction (PCR) assay $[10,11]$. PCRs were performed with the GoTaq G2 Hot Start Green Master Mix (Promega, Madison, WI, USA) in an Applied Biosystems 2720 Thermal Cycler (Thermo Fisher Scientific, Waltham, MA, USA). Electrophoresis were performed on $1.5 \%$ agarose gels stained with $2 \%$ GelRed (Biotium, Hayward, CA, USA). Chi square tests were conducted to investigate the effect of the host species, sampling period (month), and sex, on the probability of successful detection of AstV RdRp genes. Statistical analyses were conducted with $R$, version 3.2.3 [12].

PCR products of the expected size were submitted for direct Sanger sequencing (Genoscreen, Lille, France). The 31 sequences obtained in this study were aligned with 112 reference AstV RdRp partial nucleotide sequences, with CLC Sequence Viewer version 7.7.1 (CLC Bio, Aarhus, Denmark). A maximum-likelihood analysis was performed Phylogenetic trees were constructed by maximum likelihood with the software PhyML 3.1 [13]. The evolutionary model was selected by Model Generator $0.85(\mathrm{GTR}+\mathrm{I}+\Gamma, I=0.10, \alpha=0.71 ;[14])$, and nodal supports were assessed with 1000 bootstrap replicates. A Bayesian Markov Chain Monte Carlo coalescent analysis was also performed, with the program BEAST, version 1.8.4 [15], and the Shapiro-Rambaut-Drummond-2006 (SRD06) nucleotide substitution model [16]. A strict molecular clock and a constant population size were selected. The analysis was performed with a chain length of 60 million generations sampled every 1000 iterations, with first $10 \%$ trees discarded as burn-in. The maximum clade credibility tree was visualized with FigTree, version 1.4.3 (http://tree.bio.ed.ac.uk/software/figtree).

None of the 79 samples collected on Mayotte tested positive for the presence of AstV. Although this negative result may be affected by the relatively small sample size and differences in sampling protocols (swabs vs droppings), it may also suggest temporal variation in AstVs shedding and circulation in bat populations, as previously documented [17]. Additional studies are thus needed before concluding that AstVs do not circulate in Mayotte bats.

In Mozambique, 52 of the 259 bats tested positive for the presence of AstV RdRp (mean detection rate $\pm 95 \%$ confidence interval: $20.1 \% \pm 4.9 \%)$. This detection rate was similar to other studies using the same PCR assay, including the one we reported on Malagasy bats $(22.5 \% \pm 6.1 \%$; [10] $)$. For the Mozambique samples, five of the ten bat species tested positive (Table 1 and Additional file 1 for details), with significant variation between species $\left(\chi^{2}=104, P<0.001\right)$. A high detection rate was found in Triaenops afer $(68.6 \% \pm$ $12.7 \%$ ), as compared to other species (Table 1). Significant variation was also found between the two sampling sessions $\left(\chi^{2}=9, P<0.005\right)$ with a higher detection rate in May $(25.3 \% \pm 6.5 \%)$ than in February $(10.1 \% \pm 6.3 \%)$, in particular for $T$. afer $\left(\chi^{2}=13, P<0.001 ; 20 \% \pm 24.7 \%\right.$ in February, and $80.5 \% \pm 12.1 \%$ in May). This variation may be associated with factors related with bat population dynamics facilitating or limiting virus transmission (e.g. population size, density, age structure, body condition $[18,19])$. No significant difference was found in AstV detection rate between males and females $\left(\chi^{2}=0.4, P<0.5\right)$.

High genetic diversity was detected among AstVs sequences obtained from Mozambican bats (pairwise distance up to $45 \%$ ), without strong support for host family or species restriction (Fig. 1 and Additional file 2 for details), as commonly described for bat AstVs [8, 10, 11, 20, 21]. Most of the detected viruses clustered in large phylogenetic lineages, in particular for Triaenops afer and Hipposideros caffer, although statistical support was limited. Sequences of AstVs detected in Nycteris thebaica and Mops condylurus were mostly highly divergent and not included in larger genetic lineages comprising viruses of same bat family or the same geographic area (Fig. 1). 


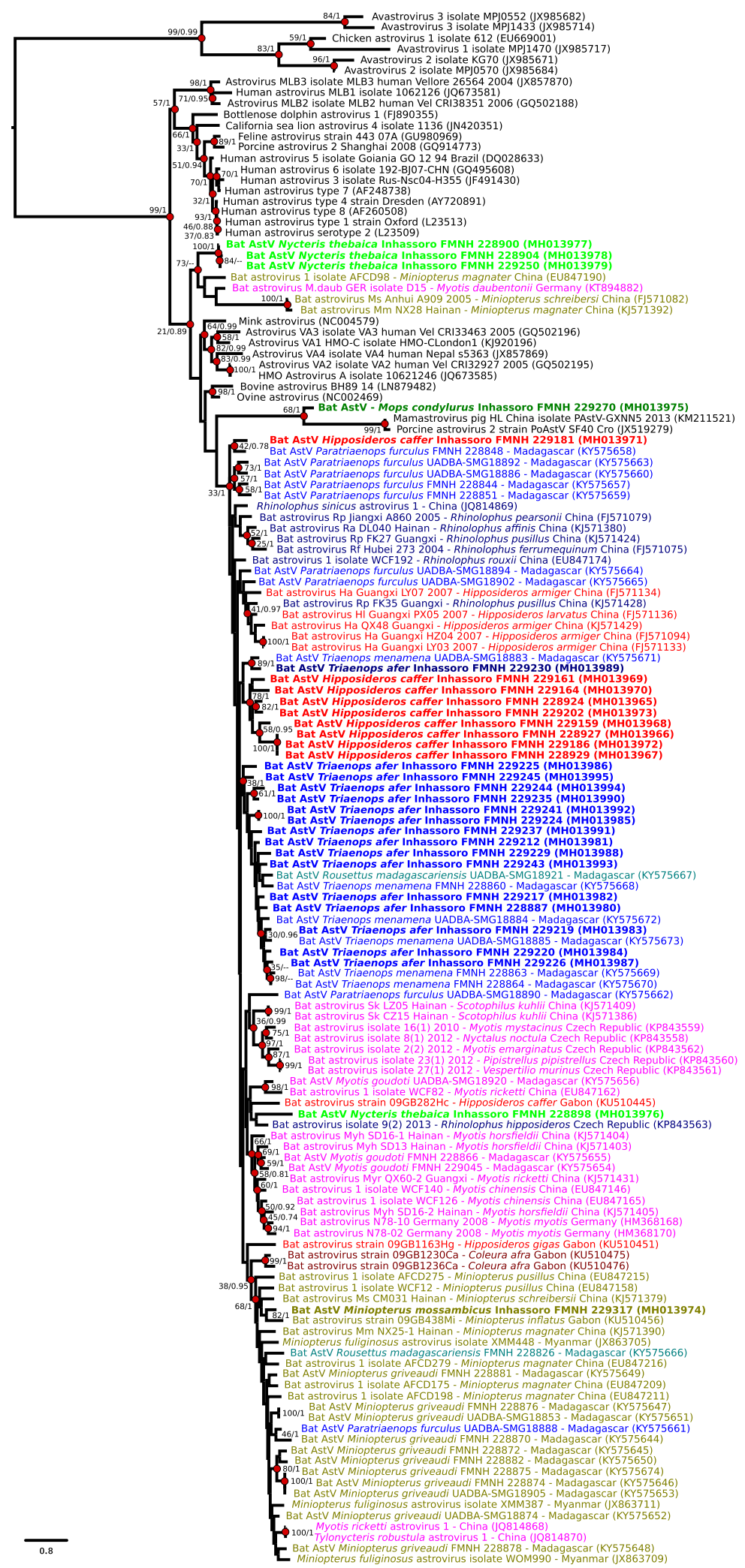

Emballonuridae

Hipposideridae

Miniopteridae

Molossidae

Nycteridae

Pteropodidae

Rhinolophidae

Rhinonycteridae

Vespertilionidae

Fig. 1 (See legend on next page.) 
(See figure on previous page.)

Fig. 1 Maximum Likelihood (ML) consensus tree derived from 143 Astrovirus (AstV) RNA-dependent RNA-polymerase partial nucleotide sequences (380 bp). Colored circles indicate nodes with bootstrap values $>70$ in the ML tree, or posterior probabilities higher than 0.7 in the maximum clade credibility tree. Sequence names in bold indicate bat AstVs detected in this study, and were colored according to the bat family. Scale bar indicates mean number of nucleotide substitutions per site

The limited genetic information available for AstVs in public databases [1], as well as the high saturation of their genome [22], considerably affects the resolution of phylogenetic trees. Current understanding of the long-time evolutionary history of Astroviridae therefore remains limited. In addition, ecological factors involved in AstV infection in bats need to be better assessed. High temporal dynamics of viral infection has been documented before [17], and the risk of spillover to other hosts, including humans, has also been demonstrated to coincide with changes in bat behavior and population structure [23]. The high propensity of AstVs for host shifts highlight the need for a better assessment of zoonotic transmission risk to human populations, particularly in relationship to some unique aspects of bat immunology and ecology.

\section{Additional files}

Additional file 1: Detailed results of Astrovirus detection in samples from Mozambique. (ODS $30 \mathrm{~kb}$ )

Additional file 2: List of the bat families and species included in the phylogenetic tree. (PDF $44 \mathrm{~kb}$ )

\section{Abbreviations}

AstV: Astrovirus; PCR: Polymerase chain reaction; RdRp: RNA-dependent RNApolymerase; VTM: Virus Transport Media

\section{Acknowledgements}

We thank Koussay Dellagi and Hervé Pascalis for the development and the management of the 'partenariat Mozambique-Réunion dans la recherche en santé: pour une approche intégrée d'étude des maladies infectieuses à risque épidémique (MoZaR)' research program.

\section{Funding}

Field research was funded by the 'Partenariat Mozambique-Réunion dans la recherche en santé: pour une approche intégrée d'étude des maladies infectieuses à risque épidémique (MoZaR)' (Fond Européen de Développement Régional, Programme Opérationnel de Coopération Territoriale) and by the 'Centre National de la Recherche Scientifique' (Projets Exploratoires Premier Soutien BATMAN). Molecular analyses were funded by tutorship institutions of the UMR PIMIT. LJ is supported by a 'Région Réunion, European Regional Development Funds (FEDER 2014-2020)' PhD fellowship. BR's post-doctoral fellowship was supported by the 'Run Emerge' European Union's Seventh Framework Program (FP7/2007-2013; Grant agreement NO 263958), the 'Fonds de Coopération Régionale, Prefecture de La Réunion' and The Field Museum of Natural History, Chicago, through the Ralph and Marian Falk Medical Research Trust. CL is supported by a 'Chaire mixte: Université de La Réunion - INSERM'. The funding agencies did not have any involvement in the study design, implementation or publishing of this study, and the research presented herein represents the opinions of the authors but not necessarily the opinions of the funding agencies.

\section{Availability of data and materials}

Sequences generated in this study have been deposited in GenBank under the accession numbers MH013965 to MH013995.

\section{Authors' contributions}

$\mathrm{CL}$ conceived and designed the study. EL, GLM, and BR collected biological material on Mayotte. SMG, GLM, ADS, and MCS collected biological material in Mozambique. FH and $L J$ performed the molecular analyses. $\mathrm{FH}$ and $\mathrm{CL}$ analyzed the data and wrote the paper. ESG and PM contributed to the project management between French and Mozambican institutions and to the first draft of the paper. All authors edited, read, and approved the final manuscript.

\section{Ethics approval}

All procedures have been evaluated and approved by an ethic committee (Agreement number A974 001; Comité d'éthique du CYROI number 114; Cyclotron Reunion Océan Indien, Sainte Clotilde, Reunion Island), and authorized by the French Ministry of Education and Research (Reference numbers 03584.01 and APAFIS\#2638-2015110616208322v1). On Mayotte, research permits were issued by the 'Direction de l'Environnement, de l'Aménagement et du Logement' (Arreté n¹58/DEAL/SEPR/2014). In Mozambique, research permits were issued by the Museum of Natural History (Ref. 01/MHN/E.27/2015) and the Ministry of Health (N'S/N/SDI/0233/15).

\section{Consent for publication}

Not applicable.

\section{Competing interests}

The authors declare that they have no competing interests.

\section{Publisher's Note}

Springer Nature remains neutral with regard to jurisdictional claims in published maps and institutional affiliations.

\section{Author details}

${ }^{1}$ Université de La Réunion, UMR Processus Infectieux en Milieu Insulaire Tropical (PIMIT), INSERM 1187, CNRS 9192, IRD 249, 2 rue Maxime Rivière (GIP CYROI), 97490 Sainte-Clotilde, La Réunion, France. ${ }^{2}$ School of Life Sciences, Biological Sciences Building, University of Kwa-Zulu Natal, South Ring Road, Westville Campus, Kwa-Zulu Natal 3630, South Africa. ${ }^{3}$ Association Vahatra, BP 3972, 101 Antananarivo, Madagascar. ${ }^{4}$ Veterinary Faculty, Eduardo Mondlane University, Maputo, Mozambique. ${ }^{5}$ Field Museum of Natural History, 1400 South Lake Shore Drive, Chicago 60605, USA. ${ }^{6}$ Instituto Nacional de Saúde, Maputo, Mozambique. ${ }^{7}$ Present Address: Institut Pasteur de Madagascar,Ambatofotsikely, 101 Antananarivo, Madagascar.

Received: 8 March 2018 Accepted: 3 June 2018

Published online: 20 June 2018

\section{References}

1. Mendenhall $I H$, Smith GJD, Dhanasekaran V. Ecological drivers of virus evolution: Astrovirus as a case study. J Virol. 2015;89:6978-81.

2. Bosch A, Pinto RM, Guix S. Human Astroviruses. Clin Microbiol Rev. 2014;27: 1048-74.

3. De Benedictis P, Schultz-Cherry S, Burnham A, Cattoli G. Astrovirus infections in humans and animals - molecular biology, genetic diversity, and interspecies transmissions. Infect. Genet. Evol. 2011;11:1529-44.

4. Fischer K, dos Reis VP, Balkema-buschmann A. Bat Astroviruses: towards understanding the transmission dynamics of a neglected virus family. Viruses. 2017;9:34.

5. Chu DKW, Leung $\mathrm{CYH}$, Perera HKK, Ng EM, Gilbert M, Joyner PH, et al. A novel group of avian astroviruses in wild aquatic birds. J Virol. 2012;86: 13772-8.

6. Rivera R, Nollens HH, Venn-Watson S, Gulland FMD, Wellehan JFX. Characterization of phylogenetically diverse astroviruses of marine mammals. J Gen Virol. 2010;91:166-73. 
7. Karlsson EA, Small CT, Freiden P, Feeroz MM, Matsen FA, San S, et al. Nonhuman primates harbor diverse mammalian and avian Astroviruses including those associated with human infections. PLoS Pathog. 2015;11: e1005225.

8. Rougeron V, Suquet E, Maganda GD, Jiolle D, Mombo IM, Bourgarel M, et al. Characterization and phylogenetic analysis of new bat astroviruses detected in Gabon, Central Africa. Acta Virol. 2016;60:386-92.

9. Waruhiu C, Ommeh S, Obanda V, Agwanda B, Gakuya F, Ge XY, et al. Molecular detection of viruses in Kenyan bats and discovery of novel astroviruses, caliciviruses and rotaviruses. Virol Sin. 2017;32:101-14.

10. Lebarbenchon C, Ramasindrazana B, Joffrin L, Bos S, Lagadec E, Le MG, et al. Astroviruses in bats, Madagascar. Emerg Microbes Infect. 2017;6:e58.

11. Chu DKW, Poon LLM, Guan Y, Peiris JSM. Novel astroviruses in insectivorous bats. J Virol. 2008;82:9107-14.

12. R Core Team R. A language and environment for statistical computing Vienna: R Foundation for Statistical Computing; 2015

13. Guindon S, Dufayard JF, Lefort V, Anisimova M, Hordijk W, Gascuel O. New algorithms and methods to estimate maximum-likelihood phylogenies: assessing the performance of PhyML 3.0. Syst Biol. 2010;59:307-21.

14. Keane TM, Creevey CJ, Pentony MM, Naughton TJ, Mclnerney JO. Assessment of methods for amino acid matrix selection and their use on empirical data shows that ad hoc assumptions for choice of matrix are not justified. BMC Evol Biol. 2006;6:29.

15. Drummond AJ, Rambaut A. BEAST: Bayesian evolutionary analysis by sampling trees. BMC Evol Biol. 2007;7:214.

16. Shapiro B, Rambaut A, Drummond AJ. Choosing appropriate substitution models for the phylogenetic analysis of protein-coding sequences. Mol. Biol. Evol. 2006;23:7-9.

17. Drexler JF, Corman VM, Wegner T, Tateno AF, Zerbinati RM, Gloza-Rausch F, et al. Amplification of emerging viruses in a bat colony. Emerg Infect Dis. 2011;17:449-56

18. Seltmann A, Corman V, Rasche A, Drosten C, Czirjak G, Bernard H, et al. Seasonal fluctuations of Astrovirus, but not coronavirus shedding in bats inhabiting human-modified tropical forests. EcoHealth. 2017;14:272-84.

19. Mendenhall IH, Skiles MM, Neves ES, Borthwick SA, Low DHW, Liang B, et al. Influence of age and body condition on astrovirus infection of bats in Singapore: an evolutionary and epidemiological analysis. One Heal. 2017;4: 27-33.

20. Kemenesi G, Dallos B, Gorfol T, Boldogh S, Estok P, Kurucz K, et al. Molecular survey of RNA viruses in hungarian bats: discovering novel astroviruses, coronaviruses, and caliciviruses. Vector Borne Zoonotic Dis. 2014;14:846-55.

21. Lacroix A, Duong V, Hul V, San S, Davun H, Omaliss K, et al. Diversity of bat astroviruses in Lao PDR and Cambodia. Infect. Genet. Evol. 2017;47:41-50.

22. Lukashov W, Goudsmit J. Evolutionary relationships among Astroviridae. J. Gen. Virol. 2002;83:1397-405.

23. Plowright RK, Foley P, Field HE, Dobson AP, Foley JE, Eby P, et al. Urban habituation, ecological connectivity and epidemic dampening: the emergence of Hendra virus from flying foxes (Pteropus spp.). Proc Biol Sci. 2011;278:3703-12.

\section{Ready to submit your research? Choose BMC and benefit from:}

- fast, convenient online submission

- thorough peer review by experienced researchers in your field

- rapid publication on acceptance

- support for research data, including large and complex data types

- gold Open Access which fosters wider collaboration and increased citations

- maximum visibility for your research: over $100 \mathrm{M}$ website views per year

At BMC, research is always in progress.

Learn more biomedcentral.com/submissions 